\title{
UCLA
}

InterActions: UCLA Journal of Education and Information Studies

Title

EPILOGUE: Meditations on the future of Latina/o archival and memory practice, research and education

Permalink

https://escholarship.org/uc/item/35n37910

Journal

InterActions: UCLA Journal of Education and Information Studies, 5(1)

ISSN

$1548-3320$

Authors

Chu, Clara M.

Dean, Rebecca

Keilty, Patrick

Publication Date

2009-02-20

DOI

10.5070/D451000645

Peer reviewed 


\title{
Epilogue: Meditations on the Future of Latina/o Archival and Memory Practice, Research and Education
}

\author{
Clara M. Chu, Rebecca Dean and Patrick Keilty \\ UCLA Department of Information Studies
}

A people who have a past, a history, and culture. A culture with history

will never die. Conquered? Maybe. Forgotten...Never!

http://www.indigenouspeople.net

History will be kind to me for I intend to write it.

History is written by the victors.

Winston Churchill

Archives as "memory-keeping" institutions or spaces play a critical role in what may constitute the historical record of a culture and its people, and whether and how they are remembered and legitimated. In referencing their European roots, Gilliland, et al. (2008) note that "archives, in the classic sense of repositories of records created and set aside by their institutions for legal, fiscal, and administrative purposes are, by definition, the instruments government and other bureaucratic structures use to effect and to document their activities" (p. 89). It is within this Western framework that archives (its records and its keepers) assert their authority. Schwartz and Cook (2002) elaborate:

Archives - as records-wield power over the shape and direction of historical scholarship, collective memory, and national identity, over how we know ourselves as individuals, groups, and societies. And ultimately, in the pursuit of their professional responsibilities, archivists-as keepers of archives-wield power over those very records central to memory and identity formation through active management of records before they come to archives, their appraisal and selection as archives, and afterwards their constantly evolving description, preservation, and use. (p. 2)

This is the context within which we encounter and consider the development of Latina/o archival and memory practice, research and education, as well as that of others outside of dominant society. Latina/o archives have to contend with the following reality:

As such, much of what we believe about the nature of archives is based upon Western ideas about the kinds of objects that a record can comprise, and the characteristics and circumstances that make that record either reliable or authentic, or, preferably, both. Little or no space exists within this paradigm for 
cultures with nontextual mechanisms for recording decisions, actions, relationships, or memory, such as those embodied in oral, aural, or kinetic traditions....Constructs of ownership, custodianship, and rights in records, linked to the dominant culture's views about who are records creators and who are subjects of records, are embedded in the laws and policy frameworks within which mainstream archival institutions and collections operate, and in the systems that manage their holdings. (Gilliland et al., 2008, p. 90)

Since the Memoria, Voz y Patrimonio (MVP) Conference, the archival literature continues to grapple with issues pertinent to Latina/o archives, including the role and power of archives, what constitutes archival and memory-keeping practices, what constitutes a record, ways to engage community in the archival process, and developing archival practice, research, and education that embraces diverse communities. Extending the work of the MVP Conference, drawing on the archival and cultural studies literature, and grounded in our experiences with under-represented communities, this epilogue offers our meditations on the future of Latina/o archival and memory practice, research, and education. In our cogitation we invoke Pierre Bourdieu's notion of symbolic power whereby the archives and archivists as social structures and agents, respectively, need to be liberated from the symbolic domination legitimized and reproduced in the classic archives.

\section{Practice: Collections}

Counter to the classic archives, the archive has been utilized as a conceptual metaphor of the imagined location where groups of ideas and materials exist and are stored together in a conceptual abstract space. These imagined archives create an abstracted referent for a community's knowledge of itself. The imaginary or conceptual archive ties the memories together of those who contribute to it, while simultaneously marking the boundaries of a community and its members. The work that is done in the imaginary or conceptual archive is a practice of resistance against the exclusionary and discriminatory practices of traditional/Eurocentric/material archives. As the articles in this section show, new practices are well under way in the Latina/o archives. Therefore, as expanded notions of the archive emerge, all aspects of archival work and discourse must be revised and redefined. We must consider then the question of what is a collection. Is a collection more than the unit in the archive that gets described, harvested by the archivist, retrieved by the scholar, and donated by the community member?

Ramírez (2009) asserts that documenting the Latina/o and Chicana/o community is the task of the archivist. Therefore, where are these collections? What is the institutional context for such collections and what challenges to 
access might this impose? Who is responsible for these collections? And in what way does this archival task challenge, augment, or produce new archival methodologies?

\section{Locating Collections}

Where are these collections? They are in an unlikely place to the traditional archivist - the local community. Chon Noriega's adventures in locating collections provide us with many lessons especially given the instance of the Harry Gamboa collection (Noriega, 2005). Gamboa is a Latino artist and a proclaimed as well as published skeptic of the historical method and the archive. Noriega recognized the absolute importance of Gamboa's papers and began the process of locating these collections. This involved building a personal relationship whereby both archivist and donor learned about their shared interests and in this case notion of social responsibility (Noriega, 2005). Both Noriega and Gamboa's framework of social responsibility valued the role of alterative histories and the critical modes of life such a history makes possible. As Noriega's process of preserving and collecting Gamboa's archive speaks to the art of locating collections to document the Latina/o community, Jones and Hernández (2009) offer ethnography as a process to document Latina/o culture as expressed in the practice of traditional medicine in Los Angeles. In these processes both community politics and personal relationships forge new opportunities for history.

\section{Institutional Context}

Archives are expensive and many delicate relationships are forged once a large institution such as a university acquires a collection from a community historically marginalized by that institution. To mitigate such a tension it is useful to consider here what makes a community archive different from a traditional archive. One difference is the accessibility of the archive to the community and the creation of that archive for the community. Of course community is not fixed and we should avoid at all costs the essentializing tendencies to conceive of community in this sense as a stable and absolute configuration of Latina/o and Chicana/o people (Ramírez, 2009). Still the question of what is the institutional context for these collections and how both present opportunities and challenges to access and use by the community should be addressed. Ramírez (2009) acknowledges the limitation of existing archival tools and offers a new model for building a Latina/o archive demonstrated in the Latino Documentation Project's account for "multiplicity of identities and communal affiliations" in its collection policy (p. 9). Therefore, given this new archival methodology that "prioritizes Latino and Latin American difference, and the importance of documenting that difference, over and above the construction of a reductive Latino identity," can 
such an ethic for multiplicity also inform institutional policy about access and use of the archive (Ramírez, 2009, p. 10)? Finally, if new archival methods privilege multiplicity in its documentation process especially of diasporic communities, as in this case, it should imbue the same value for multiplicity in regards to whom the archive aims to serve.

\section{Responsibility}

The archive as a neutral historical location whereby archivists neatly form the narratives of dominant cultural groups is widely rejected in archival literature today. The actor necessarily interrogated in this traditional notion of the archive is the archivist and the resulting professional practices, which enforce and establish what counts as the historical record. Ramírez (2009) effectively articulates the unique role of the Latina/o archivist and its direct opposition to this previous vision of the archivist's role and responsibility. He states that, "For the Latino and Latina archivist, this role becomes all the more heightened precisely because she or he is often faced with the task of documenting communities that have been rendered historically ephemeral through, among other things, racism, classism and xenophobia" (p. 1). Further, Ramírez (2009) identifies the archivist as a "seminal and politically charged role of re-inscribing Latino lives into existing historical narratives and of retrieving previously existent notions of self and community" ( $p$. 1). Therefore, the responsibility for these collections is largely upon the archivist, who engages community in the political project of re-inscribing Latina/o lives into the archive.

\section{New Archival Methodologies}

The current history of Latina/o archives documented in this special section allows us to reengage with the question of what counts as a collection and what role does the archivist and institution play in preserving these collections. New archival tools are in use fashioned to archive difference and disaggregate identity and essentialist notions of community to effectively disrupt the historical record and articulate memory of Latina/o lives and experience. What the case of the Latina/o archives teaches us is that many revisions are overdue, most notably to collection policies across the archival field.

\section{Research}

Archival research must move toward a more critical engagement. While the conference "Memoria, Voz y Patrimonio" was the first conference of its kind, archives must continue to become an area of study applied to race, ethnicity, postcolonial nationality, transnationality, gender and sexuality, and the variety of 
"identity-constituting, identity-fracturing discourses" (Sedgwick, 1993, p. 9). As Ramírez (2009) has shown, issues of identity and subjecthood cannot be extracted from archival issues, just as Derrida (1995) has shown that the very development of the Western archive is an institutional regulation and a psychological impulse rooted in oedipal obsession and fear of death and destruction. Taking from Clifford (1988), one can see the ways in which Western notions of archives proceed "from specific assumptions about temporality, wholeness, and continuity" (p. 215). In Western collections, writes Clifford (1988), "time is generally thought to be linear and irreversible-implies a rescue of phenomena from inevitable historical decay or loss" (p. 231). Cohandas (1999) has shown the way in which these Western assumptions have been imposed on native objects as a part of the social and economic subjugation of native cultures. The notion of "authenticity" has been especially pervasive.

"Authenticity," writes Cohandas (1999), "is not an essential trait of objects or practices but a discursive boundary-marking construction specifically associated with late-Victorian anthropological imaginings of "primitive' societies" (p. 143). In order to form a hierarchical relationship between the West, viewed as superior, and non-Western cultures, viewed as inferior, Western colonizers distinguished themselves as "modern" and the colonized population as "premodern," defining the objects of colonized cultures as unmarked by colonizing influence, therefore culturally "pure" and "authentic" (p. 146), revealing as well the way in which "authenticity" is constructed in the present rather than the past.

Moreover, archival studies - and information studies more broadly — must also engage critically material conditions and historical context. According to Ronald Day (2001), "a critical ethics does not have a transhistorical or moral sense from which to be certain, but instead, operating out of a critical relationship between such senses and material resistances to these senses, it attempts to articulate a historical presence that responds to material necessity, even as it must historically do so from a critical relation to the ideal" (p. 118). Working to undercut reified notions of information-where information and information professionals are neutral agents-Day (2001) invokes Benjamin's critical responsibility and contends that

In a world where responsibility and thus community are increasingly mediated by the presence and promise of the legal State, where value and conditions of value are determined by industrial powers, and where knowledge and conditions of knowledge are mediated by statistical information, critical interventions upon modernity are forms of risk that work against reified information and work from truly material information. (p. 119) 
Indeed, information professionals are not neutral actors in information work. Rather, they are making profound judgments about information that have material consequences on any sense of informed public.

Additionally, as part of that critical engagement, archival studies must end the false binary between theory and practice. As Day (2001) notes, "Theory and practice exist in opposition when practice is simply seen as the application of theory and theory is seen as the abstraction of practice. A theory and practice distinction exists only in terms of representation and an idealistic and positivist understanding of the relation of words and things, concepts and empirical facts" (p. 119). Instead, critical theory is a form of practice by engaging "the reification of the world as the practice of society and thought" (Day, 2001, p. 119). Positivist thought, according to Day (2001), "cannot account for theory as a form of practice because it cannot account for empirical facts as social or linguistic constructs and, conversely, social or linguistic constructs as empirical facts" (p. 119).

Finally, taking from Harris (2000), Gilliland \& McKemmish (2004) have argued for new social science methods in archival studies that respect the culture and knowledge systems of the communities engaged with the research. Ethnography as applied by Jones and Hernández (2009) is an example of what Gilliland \& McKemmish (2004) suggest as a step forward, advocating research teams that include and respect local and indigenous communities. Arguing against the "dualism inherent in positivism and interpretivism" (p. 170), they continue,

Liberation may well lie in the challenge of applying the apparent opposites of interpretive and positivist approaches to studying archival phenomena. In part this may lead us to redefine, even refigure, the phenomena of interest to us. In part it may lead to understandings that some phenomena in our world behave in ways which are susceptible to being seen from a positivist perspective, while others are more readily understood from an interpretivist viewpoint. And perhaps the creative tension generated will lead us to yet other ways of seeing.

\section{Education}

Education is perhaps the key to developing culturally-appropriate Latina/o archives. McKemmish, Gilliland, and Ketelaar (2005) suggest likewise: "One of the most powerful tools available to archival science for building more consistent and robust archival practices and raising the profile of archival issues globally within a comparatively rapid timeframe is professional education" (p. 9). Although education shows much promise, they also recognize that "while education is potentially a critical tool in empowering local and indigenous communities, it can also be used to subvert their traditional ways of knowing and recording. It can create, in effect, a new form of colonization by reshaping local 
practices for creating, recording, and preserving knowledge" (p. 9). The critical question they then ask is: "How do we build professional expertise in these communities without at the same time compromising the integrity of local and indigenous practices and knowledge systems, or ignoring or giving lower priority to the most pressing needs of individual communities?" (p. 9). From our experience with under-represented communities it may be more helpful to try to unpack the notion of "professional expertise" in relation to "community/cultural practice" (i.e., is "professional" privileged over "other" forms of memory-keeping practices?) in order to interrogate, rethink, and reformulate archival education around matters of who will teach, who will learn, how it will be done, what the focus of the education will be, how it will be delivered, who will provide the leadership, and who will speak for the diverse constituencies.

In an international collaboration, the Pluralizing the Archival Paradigm through Education project, Gilliland et al. (2008) have examined the extent to which record- and memory-keeping practices of diverse communities are addressed in archival education. In their study of 17 Pacific Rim countries on both sides of the ocean, Gilliland et al. (2008) found that archival education "does not yet address in a systematic and sophisticated fashion the issues raised by consideration of the challenges associated with pluralizing the archival paradigm, the recordkeeping and archival educational needs of Indigenous and minority communities, and the findings of educational research relating to pedagogical strategies for diverse communities" (p. 110). This study that included western Canada and the western United States has implications for archival education in the United States and the need to change the predominantly Eurocentric programs. However, the Society of American Archivists (SAA) Council which approved the "Guidelines for a Graduate Program in Archival Studies" in January, 2002 makes no reference to "cultural diversity," "race," or "ethnicity" but rather diversity of disciplinary base (history or LIS) and diversity of institutions and institutional homes and diversity of specialties in order to provide students with a diversity of options within a common core of archival education. This broad interpretation of "diversity" provides little guidance and no institutional mandate for reconfiguring archival education in the United States that will concern itself with Latina/o archives.

Despite the SAA Guidelines, Anne Gilliland and Elizabeth Yakel have forged ahead in the eight-university initiative of the leading archival education programs in the U.S. to train and support future archival faculty. "Building the Future of Archival Education and Research" (http://aeri.gseis.ucla.edu/aeri.htm), funded by a 4-year grant from the Institute of Museum and Library Services (IMLS), Laura Bush 21st Century Librarian Program, is applying a new methodology to reframe not only the canon of archival theory and practice, but 
also the pedagogy whereby it is conveyed, in order to address the diversity challenges faced by the archival field.

Other efforts to engage new educational practices include the use of oral history and video documentary as demonstrated by Knowledge River student Annie Smith of the University of Arizona. "Kill the Indian, Save the Man" (http://www.youtube.com/watch?v=L6PU7eNrJnE) is a video Annie made, using poetry, historical photographs, and personal oral history to document the elimination of Native Indian language resulting in the death of life, identity, culture, and family-losses that are impossible to reclaim. The archival literature provides new theories and approaches with diverse communities in mind. For example, Dunbar (2006) introduces critical race theory (CRT) to archival discourse which has implications for education, and Shilton \& Srinivasan (2007) propose the practice of participatory appraisal and arrangement for multicultural archival collections which can be integrated in the teaching of archival appraisal and management. Lastly, examples of curriculum that engages Latina/o archives can be found at UCLA and the University of Arizona's (UA) School of Information Resources and Library Science, where its Knowledge River program focuses on the study of library and information issues, services, and technologies related to Hispanics and Native Americans (http://sirls.arizona.edu). At UCLA, the American Archives and Manuscripts course taught by Anne Gilliland places diversity front and center, and Community-Based Archival Practices was recently co-taught with Chicano/a Studies and Film, Television, and Digital Media scholar Chon Noriega, and at UA a course on Documenting Diverse Cultures and Communities is offered.

\section{Conclusion}

"Frameworks for the selection, collection, arrangement and description, preservation and accessibility of archives are...closely linked to societal processes of remembering and forgetting, inclusion and exclusion, and the power relationships they embody" (McKemmish et al., 2005, p. 147). As such, Latina/o history, knowledge, and culture depend on the keeping and preservation of Latina/o archives and memory. Archives and memory are engaged in the intersubjective space of "professional" and "community" practice, and of memory/history as fixed, transmitted, lived, or imagined. Latina/o communities, thus, are called upon to assume their agency in Latina/o archival and memory practice, research, and education. The future of the Latina/o archive is located in inserting itself in the discipline of archival studies, and mediating multiple or expanded archival frameworks.

\section{References}


Cohandas, M. (1999). Elizabeth Hickox and Karuk Basketry: A case study in debates on innovation and paradigms of authenticity. In R. Philips \& C. Steiner (Eds.), Unpacking culture: Art and commodity in colonial and post-colonial worlds. Berkeley: University of California Press.

Clifford, J. (1988). The predicament of culture. Cambridge, MA: Harvard University Press.

Day, R. (2001). The modern invention of information: Discourse, history, and power. Carbondale: Southern Illinois University Press.

Derrida, J. (1995). Archive fever: A Freudian impression. Chicago: University of Chicago Press.

Dunbar, A. W. (2006). Introducing critical race theory to archival discourse: Getting the conversation started. Archival Science, 6, 109-129.

Gilliland, A., \& McKemmish, S. (2004). Building an infrastructure for archival research. Archival Science, 4, 149-197.

Gilliland, A., McKemmish, S., White, K., Lu, Y., \& Lau, A. (2008). Pluralizing the archival paradigm: Can archival education in Pacific Rim communities address the challenge? The American Archivist, 71, 87-117.

Harris, V. (2000, September). Law, evidence and electronic records: A strategic perspective from the global periphery. ICA Seville. Available from http://www.archivists.org.au

Jones, M., \& Hernández, C. (2009). Latina/o traditional medicine in Los Angeles: Asking about, archiving, and advocating cultural resources. InterActions: UCLA Journal of Education and Information Studies, 5(1), Article 2.

McKemmish, S., Gilliland, A. \& Ketelaar, E. (2005). "Communities of memory": Pluralising archival research and education agendas. Archives and Manuscripts, 33, 146-174.

Ramírez, M. (2009). The task of the Latino/a Archivist: On archiving identity and community. InterActions: UCLA Journal of Education and Information Studies, 5(1), Article 1.

Schwartz, J., \& Cook, T. (2002). Archives, records, and power: The making of modern memory. Archival Science, 2, 1-19.

Sedgwick, E. K. (1993). Tendencies. Durham: Duke University Press.

Shilton, K. \& Srinivasan, R. (2007). Participatory appraisal and arranement for multicultural archival collections. Archivaria, 63, 87-102.

The Society of American Archivists. (2002). Guidelines for a graduate program in archival studies. Retrieved January 3, 2009, from http://www.archivists.org/prof-education/ed_guidelines.asp\#_ftn1

\section{Authors}


Clara M. Chu is an Associate Professor of Information Studies as well as an affiliated faculty with the Department of Asian American Studies at UCLA. Having published, presented and consulted internationally in English and Spanish, she is a leading voice on multicultural library and information issues, and serves on the editorial boards of information studies and Asian Pacific American Studies journals. She is recipient of the American Library Association's 2008 Library Diversity Research Honor, among other awards.

Rebeca Dean is a doctoral student in the Department of Information Studies at UCLA in the School of Education and Information Studies. She is also working towards a concentration in Women's Studies. Rebecca received a BA from New York University and a MLIS at Pratt Institute. Her research interests include critical and feminist approaches to notions of evidence, documentation, surveillance, infrastructure, and knowledge production. She can be reached at becdean@gmail.com.

Patrick Keilty is a PhD student in the Department of Information Studies, with a concentration in Women's Studies, at UCLA. His research explores feminist and queer philosophical approaches to knowledge structures and information policy/ ethics. He is also interested in relations concerning Internet culture, performance, self-fashioning, and the body. 